\title{
Materials Research and Development Opportunities in Fusion Reactors
} S MUKHERJEE and N I JAMNAPARA*

\author{
FCIPT Division, Institute for Plasma Research, Bhat, Gandhinagar 382 428, India
}

(Received on 06 December 2014; Accepted on 28 July 2015)

\begin{abstract}
Next generation fusion reactors would demand new materials and technologies that can sustain extreme nuclear environment. Materials development activities related to structural materials, shields, superconducting magnets, breeder materials, plasma facing materials, function materials and coatings have been accelerated in the last two decades. Out of these, recent research activities are focused mainly on structural materials, plasma facing materials and breeder materials. Generation of appropriate nuclear testing and materials characterization facilities is also required to complement such materials research $\&$ development activities. In this context, an overview of the scenario of materials R\&D activities in India and abroad has been discussed in this chapter.
\end{abstract}

Keywords: Fusion reactor; materials; ceramics; irradiation; blanket; divertor.

\section{Introduction}

Thermonuclear fusion of two hydrogen isotopes results in release of energy and energetic neutrons which can be utilized for electricity generation. Out of various hydrogen isotope reactions viz. D-D, D-T \& T-T (D: Deuterium, T: Tritium), the D-T reaction has the largest cross-section at the lowest energy. D-T Fusion reaction can be conducted by different confinement methods viz., gravitational confinement, inertial confinement, and magnetic confinement. While different fusion confinement techniques are being explored, the most widely pursued technique is magnetic confinement fusion. A tokamak is a device which uses magnetic field to confine plasma to the shape of a torus. Such magnetic confinement is required since no solid material could withstand extremely high temperatures of plasma. Tokamak is one of the several types of magnetic confinement devices, and is one of the most researched devices for producing controlled thermonuclear fusion power. Tokamaks such as DIII-D in San Diego, USA; Joint European Torus (JET), Culham UK; Tore Supra at CEA, Cadarache, France, etc. are being used for thermonuclear fusion. In November, 2006, seven partner countries viz. European Union, Japan, USA, Russia, South Korea, China and India joined hands to set up a nuclear fusion reactor named International Thermonuclear Experimental Reactor (ITER) at Cadarache, France and the first plasma shot is scheduled in 2020. "Aditya" is India's first tokamak developed by the Institute for Plasma Research, Gandhinagar. Subsequently, as the next step, a steady state tokamak (SST-1) reactor has been commissioned and India has been working on its domestic fusion programme as well.

The fusion of deuterium (D) and tritium (T) under magnetic confinement would lead to generation of energetic $14.1 \mathrm{MeV}$ neutrons by the following reaction (Naujoks, 2010):

$\mathrm{D}+\mathrm{T} \rightarrow{ }^{4} \mathrm{He}(3.517 \mathrm{MeV})+\mathrm{n}^{0}(14.069 \mathrm{MeV})$

The D-T reaction (eq. i) yields highly energetic 14.1 MeV neutrons which can be utilized to generate fuel (T) from Li as well as extract energy from the kinetic energy of neutrons. This is expressed by the following equation:

*Author for Correspondence: E-mail: nirav@ipr.res.in 


$$
{ }^{6} \mathrm{Li}_{3}+\mathrm{n}^{0} \rightarrow{ }^{4} \mathrm{He}_{2}+{ }^{3} \mathrm{~T}_{1}+4.78 \mathrm{MeV}
$$

Thus, Li utilizes the fast moving neutrons to generate $\mathrm{T}$ fuel and heat, which is later on converted to electricity. This conversion of energy of neutrons to heat and electricity is done by the blanket module of the reactor as discussed in section 2.2. A cutaway view of the ITER model is indicated in Fig. 1 (Suri et al., 2010). This high energy of neutrons also leads to severe damage of structural and functional materials in the reactor, i.e. radiation damage, generation of transmutation products and consequences in the mechanical and metallurgical properties thereof. It is therefore necessary to understand the type of environments prevailing in different sub-systems of the fusion reactor and their operational requirements. Fig. 2 indicates a schematic of various subsystems (Suri et al., 2010).

As shown in Fig. 2, the magnetically confined plasma core has a temperature of $\sim 5$ million ${ }^{\circ} \mathrm{C}$. The energy from $14.1 \mathrm{MeV}$ neutrons has to be utilized for $\mathrm{T}$ production and electricity generation. The sub- assemblies and their functional requirements are spelt out in Table 1 (Baluc et al., 2007).

\section{Materials-related Challenges in Fusion Environment}

As discussed in the previous section, many materials research and development needs have been generated for building a suitable fusion reactor plant. Most of the $R \& D$ activities on materials for fusion reactors is mainly focused on plasma facing (first wall and divertor), breeder materials and structural materials. This includes materials development, fabrication technologies, characterization and functional validation of the developed materials. A brief overview of the materials R\&D needs have been summarized in the following sections.

\subsection{Plasma-facing Components and Divertor}

The hot plasma confinement by magnetic confinement in a tokamak reactor involves plasma-materials interaction. The first solid surface of the reactor facing

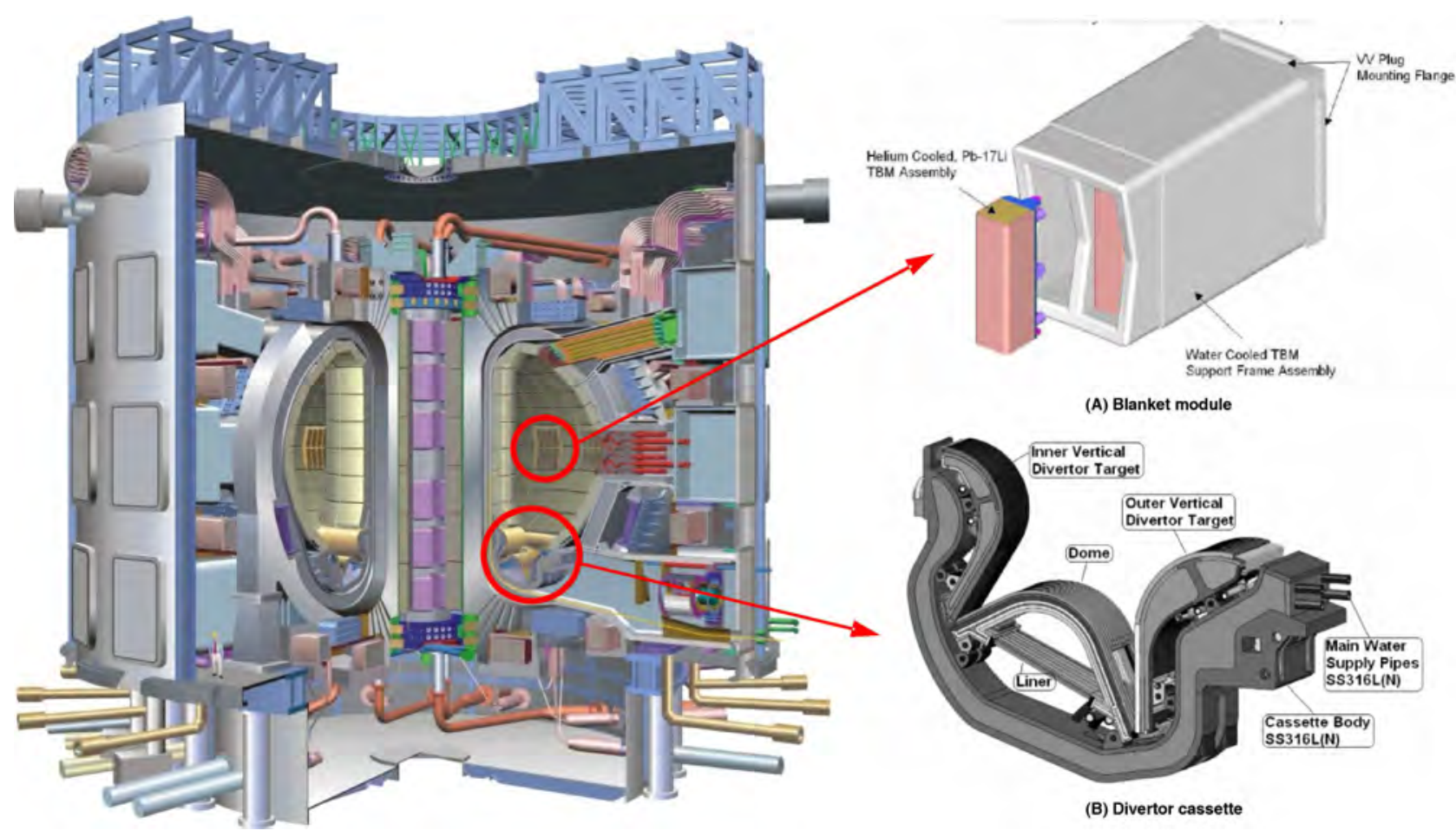

Fig. 1: (A) Cutaway view of ITER model showing the glimpse of various sub-systems such as first wall, divertor, breeder blanket module, superconducting magnetic coils, vacuum vessel etc. (B) gives a magnified view of the test blanket module (C) magnified view of the divertor cassette assembly [Ref: Suri et al. (2010)] 
Table 1: Generic information about subassemblies and their functional objectives [Ref: Baluc et al. (2007)]

\begin{tabular}{|c|c|c|c|}
\hline & First wall & Divertor & Breeder Blanket \\
\hline $\begin{array}{l}\text { Functional } \\
\text { objectives }\end{array}$ & $\begin{array}{l}\text { To shield subassemblies from } \\
\text { thermal loading and plasma } \\
\text { exposure }\end{array}$ & $\begin{array}{l}\text { To extract particles / He dust, survive } \\
\text { high heat flux }\end{array}$ & $\begin{array}{l}\text { To breed T fuel, utilize } 14.1 \mathrm{MeV} \text { neutrons, } \\
\text { shield sub-assemblies from neutrons, } \\
\text { extract heat for electricity generation }\end{array}$ \\
\hline $\begin{array}{l}\text { Plasma facing } \\
\text { materials }\end{array}$ & $\begin{array}{l}\text { W, W-based alloy, W coated } \\
\text { SiC, Be, W coated ODS/ } \\
\text { RAFM steels, flowing liquid Li }\end{array}$ & $\begin{array}{l}\text { W-based alloy (ODS-W etc.), W-coated } \\
\mathrm{SiC}_{\mathrm{f}} / \mathrm{SiC} \text {; flowing liquid metal: } \\
\mathrm{Li}, \mathrm{Ga}, \mathrm{Sn}, \mathrm{Sn}-\mathrm{Li}\end{array}$ & As in the first wall \\
\hline $\begin{array}{l}\text { Neutron } \\
\text { multiplier }\end{array}$ & - & - & $\mathrm{Be}, \mathrm{Be}_{12} \mathrm{Ti}, \mathrm{Be}_{12} \mathrm{~V}, \mathrm{~Pb}$ \\
\hline $\begin{array}{l}\text { Tritium breeding } \\
\text { material }\end{array}$ & $g-$ & - & $\begin{array}{l}\text { Liq. } \mathrm{Li} \text {, Eutectic } \mathrm{Pb}-\mathrm{Li}, \mathrm{Li} \text { based ceramic } \\
\text { pebbles }\left(\mathrm{Li}_{2} \mathrm{O}, \mathrm{Li}_{4} \mathrm{SiO}_{4}+2.5 \% \mathrm{SiO}_{2}\right. \\
\left.\mathrm{Li}_{2} \mathrm{TiO}_{3}, \mathrm{Li}_{2} \mathrm{ZrO}_{3}, \mathrm{LiAlO}_{2}\right)\end{array}$ \\
\hline $\begin{array}{l}\text { Structural } \\
\text { material }\end{array}$ & $\begin{array}{l}\text { RAFM steel, ODS steel, } \\
\text { V-based alloy, } \mathrm{SiCf} / \mathrm{SiC}\end{array}$ & ODS steel, W-based alloy & $\begin{array}{l}\text { RAFM steel, ODS steel, V-based alloy, } \\
\text { SiCf/SiC }\end{array}$ \\
\hline Coolant & - & Water, He & Water, $\mathrm{He}$, Eutectic Pb-Li, Li \\
\hline
\end{tabular}

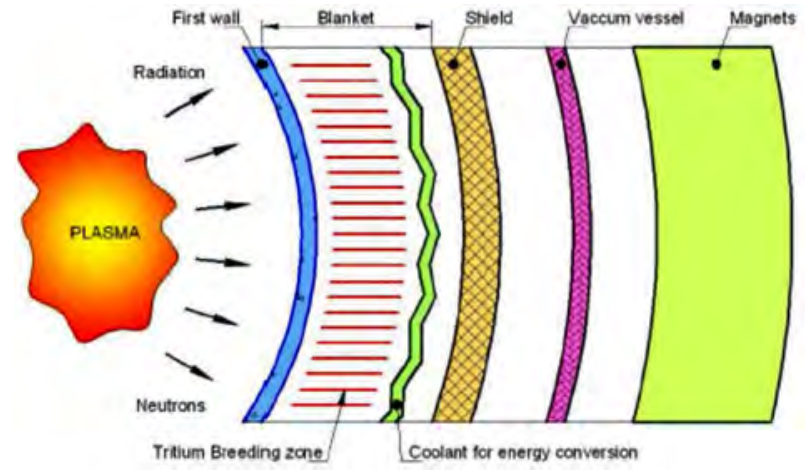

Fig. 2: A schematic diagram of arrangement of sub-systems in a tokamak reactor. [Ref: Suri, Krishnamurthy et al. (2010)]

the hot plasma is known as the "First wall" and the assembly is often referred to as plasma-facing components (PFC), whereas divertor is a device (or assembly) that allows the online removal of material and $\mathrm{He}$ ash from plasma. The first wall surface faces impact of energetic particles leading to erosion of the surface and irradiation damage, and leads to trapping of $\mathrm{D}$ or $\mathrm{T}$ in re-deposited layers of eroded species leading to a radioactive inventory buildup in the reactor. The impinging energetic particle spectrum varies across the poloidal circumference of the tokamak reactor, and hence different materials can be used depending on the particle energy and flux at a given location in the reactor. Fig. 3 as reported by Reith and co-workers (Rieth et al. 2013) provides an idea about the first wall and blanket assembly. As indicated in Fig. 3, area (1) indicates the first wall typically associated with the plasma facing side of the blanket assembly, area (2) indicates the plasma

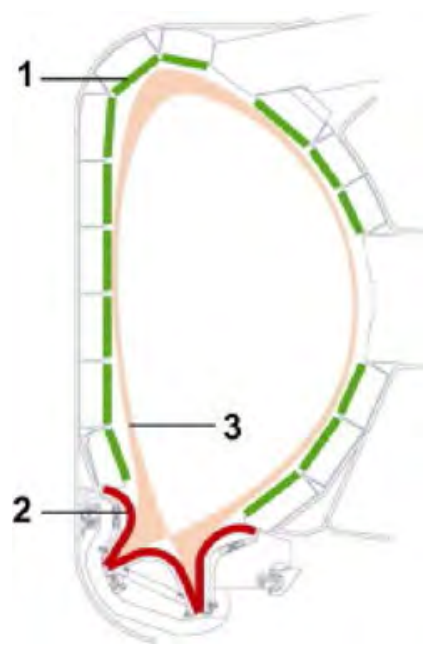

Fig. 3: The illustration shows the cross-section of a tokamak. (1) The plasma facing part of the blanket boxes - so called first wall. (2) The high heat flux cooling layout of the divertor. (3) The magnetic field lines which direct exhaust particles (mainly He) to divertor target plates [Ref: Rieth et al.(2013)] 
facing side of the divertor and area (3) indicates the magnetic field lines which exhaust the exhaust particles to divertor target plates. The PFCs have to face high heat flux $\left(<1 \mathrm{MW} / \mathrm{m}^{2}\right.$ for blanket first wall and up to $20 \mathrm{MW} / \mathrm{m}^{2}$ for divertor target plates), suffer from erosion of PFCs due to particle impingement. Reaction of $\mathrm{D}$ or $\mathrm{T}$ with eroded particles also poses a threat of radioactive dust.

The selection of material for the first wall is critical. On erosion, low $\mathrm{Z}$ materials are fully ionized in the central plasma and only radiate bremsstrahlung, the high $\mathrm{Z}$ elements still have bound electrons that emit line radiation which leads to strong plasma cooling (Schmid and Roth, 2010). On the other hand, low Z materials (viz., $\mathrm{C}, \mathrm{Be}$, etc.) have higher erosion rates than high $\mathrm{Z}$ elements (viz. W, Mo, etc.). The ITER first wall with a heat flux $<1 \mathrm{MW} / \mathrm{m}^{2}$ considers Be or $\mathrm{W}$ as plasma-facing material. One of the reasons attributed to replacing carbon-based PFCs to W-based PFCs is the reduction of hydrogen or tritium retention (Philipps 2011). However, under high hydrogen fluence and low temperatures $(<600 \mathrm{~K})$, blistering of $\mathrm{W}$ has been observed (Neu, 2010). Be poses health hazards and hence is still under evaluation stage. This $\mathrm{W}$ can either be coated on the structural material of first wall (RAFM steel) by thermal spray technique (e.g. vacuum plasma spray) or can be fixed as a solid tile. The fabrication process (thermal spray coating or fabrication of solid tile block) for affixing on the structural component of the first wall is being investigated globally.

The divertor assembly (Fig. 4) (Griffith, 2008) on the other hand considers both low $\mathrm{Z}$ and high $\mathrm{Z}$ materials. The main function of divertor assembly is to remove the scrape off layer (SOL) (mainly He dust), shield subsequent sub-assemblies from very high heat fluxes $\left(10-20 \mathrm{MW} / \mathrm{m}^{2}\right)$ and extract heat out of the divertor. W and Carbon Fibre Composites (CFCs) have been the preferred choice of materials for such divertor target plates in ITER. In order to improve the erosion resistance, oxide dispersion strengthening concept is being explored in target plates or first wall components and powder metallurgical processing routes are reported to be promising. (Rieth et al. 2013) has reported development of ODS-tungsten alloys

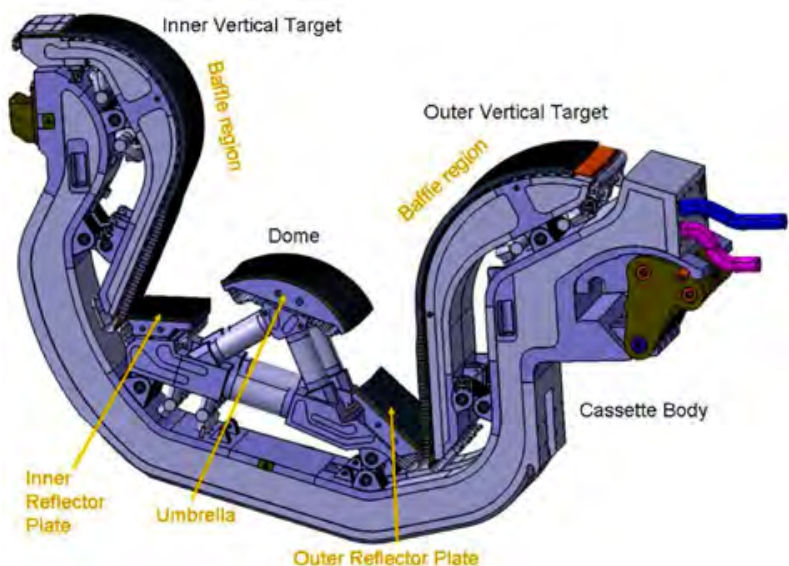

Fig. 4: Illustrative diagram of ITER divertor cassette assembly. Image emphasizes the arrangement of plasma facing components and the cooling arrangement provided to extract the heat. Multiple casettes together will be assembled in the torus to form a divertor of reactor [Ref: Griffith (2008)]

such as $\mathrm{W}-2 \mathrm{Y}_{2} \mathrm{O}_{3}, \mathrm{~W}-2 \mathrm{La}_{2} \mathrm{O}_{3}$ etc. in Europe, while $\mathrm{W}-\mathrm{La}_{2} \mathrm{O}_{3}, \mathrm{~W}-\mathrm{TiC}, \mathrm{W}-\mathrm{TaC}$ and $\mathrm{W}-\mathrm{Y}_{2} \mathrm{O}_{3}$ are being reported to be developed in China (Yan et al., 2013). Fabrication processes such as wet chemical method, mechanical alloying, sintering of pure and doped $\mathrm{W}$ by spark plasma sintering, resistance sintering under ultra-high pressure are being pursued. Properties of such W-based PFCs are also being studied through embrittlement studies, blistering, hydrogen retention, radiation damage and high heat flux testing. Another challenge to divertor design is the fabrication of an appropriate heat sink along with $\mathrm{W}$ armour.

The heat from the armour tile has to be extracted, for which a heat sink made of $\mathrm{CuCrZr}$ - a precipitation hardened copper alloy has been reported as candidate material (You et al., 2013; Rotti et al., 2014). An SS 316 (LN) grade pipe brazed through $\mathrm{CuCrZr}$ alloy shall circulate water for cooling and heat extraction purpose. The joining of this $\mathrm{CuCrZr}$ alloy with refractory armour material such as $\mathrm{W}$ is a challenge owing to the large coefficient of thermal expansion (CTE) difference. Vacuum brazing of W/CuCrZr and $\mathrm{C} / \mathrm{CuCrZr}$ has been found successful as a joining technique. W/Cu tile fabrication using oxide free high conductivity (OFHC) $\mathrm{Cu}$ casting in vacuum followed by brazing of $\mathrm{W} / \mathrm{Cu}$ with $\mathrm{CuCrZr}$ has been found promising. Studies on functionally graded coatings of 
$\mathrm{W}-\mathrm{Cu}$ on $\mathrm{CuCrZr}$ alloys are being pursued as a promising solution. One of the limitations of $\mathrm{W} / \mathrm{Cu}$ functionally graded materials (FGMs) is loss of strength at elevated temperatures due to presence of $\mathrm{Cu}$. As a solution to this, recent studies (You et al., 2013) have been reported on W/CuCrZr FGMs. Porous W skeletons infiltrated with CuCrZr alloy melt was prepared in the form of functionally graded composite as promising materials for divertor applications. Graded composite samples of $\mathrm{W} / \mathrm{CuCrZr}$ in 1:1 ratio were reported promising for further development. Apart from this, novel concepts such as liquid metal (Li) plasma-facing components are being evaluated at Princeton Plasma Physics Laboratory. Other concepts involve vaporization of $\mathrm{Li}$ such as tungsten alloy with $\mathrm{Li}$, wherein lithium would get evaporated and would thus be able to sustain the heat fluxes (Wong et al. 2001). Areas such as tritiated water corrosion of SS316 (LN) tubes are also important as the radiolytic and decomposition products enhance the corrosion rates (Bellanger, 2008). Further, presence of tritium would add to possible stress corrosion cracking issues, which need to be studied and mitigated.

\subsection{Test Blanket Module}

The fusion reactor programme is driven by the ultimate goal of developing large-scale power plants for production of electricity. The success of a fusion power plant is dependent on the high-grade heat extraction capability and efficiency of the tritium breeding blankets (Kumar et al., 2008). A blanket module as the name suggests is an assembly which blankets the core of the fusion reactor and utilizes the energy of neutrons to generate $\mathrm{T}$ fuel and heat for electricity production. Thus, the main function of a breeder blanket module is to generate $\mathrm{T}$ fuel from $\mathrm{Li}$ by utilizing the $14.1 \mathrm{MeV}$ neutrons generated from reactor core; to extract the heat for electricity generation purpose generated from the n-Li reaction and shield the other sub-systems from the radiation damage by the energetic neutrons. This can be achieved by appropriate design concepts, selection and or development of appropriate breeder materials and their processing techniques and the choice of appropriate structural material with relevant compatibility with breeder material. Since the T can be generated from reacting the neutrons with ${ }^{6} \mathrm{Li}$ (see eq. ii), all the breeder materials are $\mathrm{Li}$ or Li-based compounds or alloys. Based on the form of $\mathrm{Li}$, the blanket design can either be categorized as liquid breeder blanket, solid breeder blanket or mixed type. Different blanket module designs with solid or liquid or dual breeder breeder concepts have been proposed by different countries which are summarized in Table 2 . The ITER reactor will be useful for testing and validating different blanket concepts as proposed by partner countries and the performance information will be helpful for development of a DEMO relevant blanket module design.

Both the solid and liquid breeder concepts have their pros \& cons. The main advantage of the solid breeder is that it offers good compatibility between breeder, structural material and the coolant. However, one of the major drawbacks of solid breeder concept is the costly fabrication and re-processing of the ceramic breeder material. Against this, the liquid breeder concept offers efficient heat \& fuel extraction, and easy maintenance. A general comparison between the two breeder blanket concepts is provided in Table 3 (Bornschein et al., 2013). The Indian Lead Lithium Ceramic Breeder (LLCB) blanket involves use of both solid and liquid breeder concepts. The conceptual sketch of the Indian TBM (LLCB) as indicated in Fig. 5 (Rajendra Kumar et al., 2012), illustrates the arrangements of the ceramic breeder columns and liquid breeder $(\mathrm{Pb}-$ 17Li) flow channels. The flow of $\mathrm{Pb}-17 \mathrm{Li}$ in the RAFM steel channels results in severe corrosion of RAFM steel. (Krauss et al., 2012) reported a dissolution rate of RAFMS at the rate of $\sim 400 \mu \mathrm{m} /$ year which is approximately equivalent to $4 \mathrm{~kg} / \mathrm{m}^{2}$ per year of TBM-dissolved corrosion products. Such dissolution of structural material would not only lead to possibility of section thinning and leak out, but also poses a threat of chocking of the flow channels due to re-deposition of dissolved corrosion products at colder zones. Apart from corrosion, another major concern is the $\mathrm{T}$ permeation into steel. The $\mathrm{T}$ generated from $\mathrm{Li}$ during the $\mathrm{Pb}-17 \mathrm{Li}$ flow path or from the ceramic pebble bed channels would permeate into the steel and thereby increase the radioactive $T$ 
Table 2: Overview of different breeding blanket concepts

\begin{tabular}{|c|c|c|}
\hline TBM design concepts & Country & Brief outline of the blanket design \\
\hline Helium Cooled Lead Lithium (HCLL) & $\mathrm{EU}$ & $\begin{array}{l}\mathrm{He} \& \mathrm{PbLi} \text { as coolant and breeder; RAFMS (Eurofer '97) as structural } \\
\text { material }\end{array}$ \\
\hline $\begin{array}{l}\text { Dual Function Lithium Lead (DFLL) - } \\
\text { He cooled quasi-static lithium lead (SLL) }\end{array}$ & China & $\begin{array}{l}\text { He as coolant; self-cooled PbLi in quasi-static condition as breeder; RAFMS } \\
\text { (CLAM steel) as structural material. }\end{array}$ \\
\hline $\begin{array}{l}\text { Dual Function Lithium Lead (DFLL) - } \\
\text { Dual cooled Lithium Lead (DLL) }\end{array}$ & China & $\mathrm{He} / \mathrm{LiPb}$ as coolant \& breeder; RAFMS (CLAM steel) as structural material; \\
\hline Lead Lithium Ceramic Breeder (LLCB) & India & $\begin{array}{l}\mathrm{He} \text { as coolant; self-cooled } \mathrm{PbLi} \text { as breeder; } \mathrm{Li}_{2} \mathrm{TiO}_{3} \text { as solid breeder; RAFMS } \\
\text { as structural material }\end{array}$ \\
\hline Helium Cooled Liquid Lithium & USA & $\begin{array}{l}\mathrm{He} \text { as coolant; self-cooled liquid } \mathrm{Li} \text { as breeder; } \mathrm{RAFMS} \text { with } \mathrm{SiC}_{f}-\mathrm{SiC} \\
\text { inserts as structural material }\end{array}$ \\
\hline Lithium Vanadium $(\mathrm{Li}-\mathrm{V})$ & Russia & $\begin{array}{l}\text { Self-cooled lithium as coolant cum breeder; Vanadium alloys as structural } \\
\text { material }\end{array}$ \\
\hline Helium Cooled Molten Lithium (HCML) & Korea & He as coolant; molten Li as breeder; RAFMS (Eurofer) as structural material \\
\hline Water Cooled Solid Breeder (WCSB) & Japan & $\begin{array}{l}\mathrm{Li}_{2} \mathrm{TiO}_{3} \text { as solid T breeder; Be pebbles as neutron multiplier; He and water } \\
\text { as coolants; } \mathrm{SiCf} / \mathrm{SiC} \text { inserts; } \mathrm{F} 82 \mathrm{H} \text { (RAFMS) as structural material }\end{array}$ \\
\hline
\end{tabular}

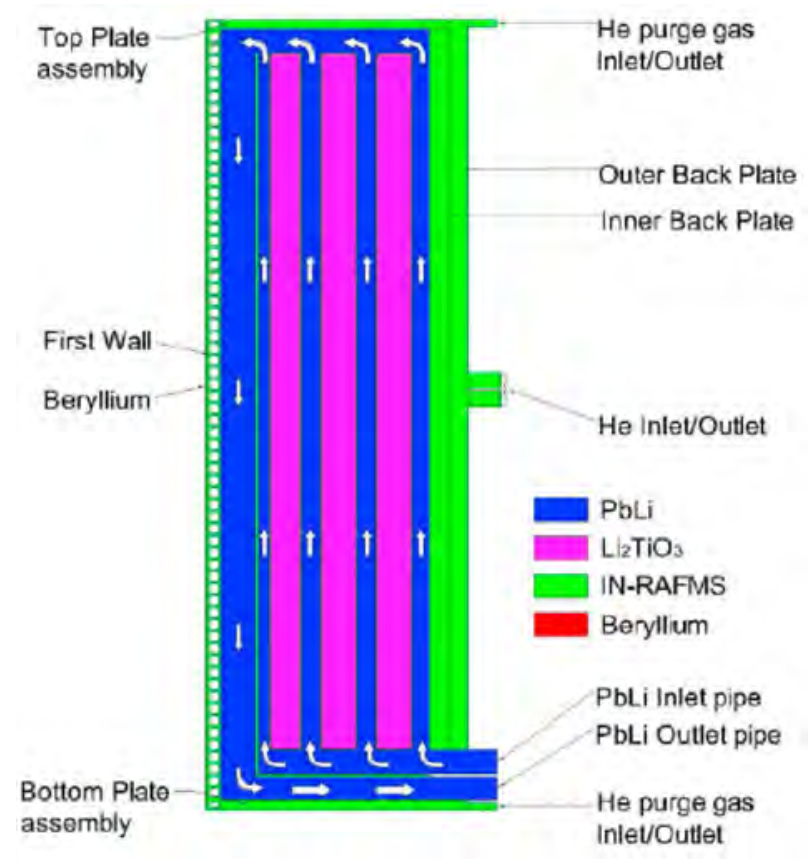

Fig. 5: Schematic diagram of Indian TBM (Lead Lithium Ceramic Breeder) concept. The arrows eutectic breeder while the columns in between (pink colour) represent solid $\mathrm{Li}_{2} \mathrm{TiO}_{3}$ breeder columns. [Ref: Rajendra Kumar et al. (2012)]

inventory buildup in the reactor, which is undesirable. The interaction of magnetic field $\mathrm{B}$ with the flowing liquid metal also induces a magneto hydrodynamic drag (MHD), which increases the corrosion rates of steel as well as increases the required $\mathrm{Pb}-17 \mathrm{Li}$ pumping pressures. Coatings have been reported to be an inherent solution to all the three major issues of blanket modules. Such coatings will need to be compatible with $\mathrm{Pb}-17 \mathrm{Li}$; resist permeation of $\mathrm{T}$ into steel with permeation reduction factor $>100$; provide electrical insulation for mitigating MHD issues and can also be coated on complex geometries (Smith et al., 2002). The coatings should have low radiation induced conductivity after neutron irradiation. A variety of coatings such as $\mathrm{AlN}, \mathrm{Al}_{2} \mathrm{O}_{3}, \mathrm{Er}_{2} \mathrm{O}_{3}, \mathrm{Y}_{2} \mathrm{O}_{3}$, $\mathrm{CaO}, \mathrm{AlN},\left(\mathrm{Cr}_{2} \mathrm{O}_{3}+\mathrm{SiO}_{2}\right)+\mathrm{CrPO}_{4}, \mathrm{ZrO}_{2}$, $\mathrm{Al}_{2} \mathrm{O}_{3}+\mathrm{FeAl}$, etc. have been explored for different blanket concepts as reported in literature survey (Jamnapara 2013). Alumina and erbia coatings have been widely reported as candidates for the ITER reactor, wherein RAFM steel is considered as structural material. The structural materials are an integral part of the blanket module and its development and testing are inevitable. Studies on structural materials in blankets have been briefly spelt out in section 2.3. 
Table 3: Comparison of solid and liquid breeder design concepts [Ref: Bornschein et al. (2013)]

\begin{tabular}{lll}
\hline & Solid breeder & Liquid breeder \\
\hline Breeder material & $\begin{array}{l}\mathrm{Ceramics}_{\mathrm{LiO}}, \mathrm{LiAlO}_{2}, \mathrm{Li}_{2} \mathrm{SiO}_{3}, \mathrm{Li}_{4} \mathrm{SiO}_{4}, \\
\mathrm{Li}_{8} \mathrm{ZrO}_{6}, \mathrm{Li}_{2} \mathrm{TiO}_{3}\end{array}$ & $\mathrm{Li}_{17} \mathrm{~Pb}_{83}$, Flibe (LiF, BeF2) \\
Neutron multiplier & $\mathrm{Be}, \mathrm{Be}_{12} \mathrm{Ti}$ & $\mathrm{Pb}, \mathrm{Be}$ \\
Coolant & $\mathrm{He}$ cooled, Water cooled & He cooled, water cooled, self cooled, dual cooled \\
Structural material & RAFM steel & RAFM steel \\
Advantages & Tritium extraction less challenging & No breeder damage or swelling; adjustable breeder composition \\
Difficulties & $\begin{array}{l}\text { Blanket replacement, tritium permeation } \\
\text { into coolant }\end{array}$ & MHD drag, corrosion, tritium permeation into coolant \\
\hline
\end{tabular}

\subsection{Structural Materials}

Structural materials for power plants are derived from existing high strength materials used for extreme environments. Materials and alloys having reduced activation elements (to reduce radioactive inventory), high resistance to creep, fatigue, low ductile to brittle transition temperatures, and capable of being used at higher temperatures under neutron irradiation are desired for fusion reactors (Baluc, 2006). After more than two decades of research, only three candidate material systems appear to have the potential to meet the low activation, high performance goals: $8-9 \mathrm{Cr}$ ferritic/martensitic steels (including reduced activation variants), $\mathrm{SiC}_{\mathrm{f}} / \mathrm{SiC}$ composites and $\mathrm{V}-\mathrm{Cr}$-Ti alloys (Bloom et al., 2007).

\subsubsection{Effect of Neutron Irradiation}

Irradiation damage occurs due to impingement of high energy particles viz. electrons, ions, neutrons, protons on the atoms of structural or functional materials, wherein the atoms are displaced from their regular lattice positions yielding Frenkel defects viz. vacancies and interstitials (Ronald and Klueh, 2001). While a few tens of $\mathrm{eV}$ are required to displace an atom, the neutrons in fusion reactors with $14.1 \mathrm{MeV}$ energy will create significant radiation damage in the irradiated material. The extent of displacement damage is expressed in terms of how often an atom is displaced from its normal lattice position during irradiation as displacement per atom or dpa. In addition to the displacement damage, neutrons also cause transmutation reactions with atoms of the irradiated material. Such transmutation products may either be another metal atom or gas atoms viz. helium and hydrogen by $(n, \alpha)$ and $(n, p)$ reactions, respectively. It is well-known that the production of small amounts of He within lattice may have pronounced effects on material properties. Vacancies become more mobile for irradiation above $0.3 \mathrm{~T}_{\mathrm{m}}$, and result in formation of dislocation and cavity. Swelling of irradiated components occurs due to cavities formed by dissolved gases. As a result, the combination of gaseous transmutant products and radiation damage has to be monitored closely in the form of He/dpa ratio. An overview of the defect production in steels for different irradiation facilities has been reported by Baluc et al. (2007) and listed in Table 4.

Overall, it can be said that radiation damage leads to issues such as radiation-induced segregation, radiation hardening and embrittlement, phase instabilities due to radiation-induced precipitation, irradiation creep, volumetric swelling due to void formation, and high temperature $\mathrm{He}$ embrittlement (Tavassoli, 2002; Baluc et al., 2011).

\subsubsection{Reduced Activation Steels}

The safety and environmental concerns in fusion reactors involve radioactivity in blanket and first wall structures. The radioactivity of the exposed fusion reactor components should be short-lived and hence, the structural material selection should involve low activation or reduced activation elements, specifically 
Table 4: Defect production in steels for various irradiation facilities [Ref: Baluc et al. (2007)]

\begin{tabular}{lcccc}
\hline $\begin{array}{l}\text { Defect production } \\
\text { (in steels) }\end{array}$ & $\begin{array}{c}\text { Fusion neutrons } \\
\text { (3-4 GW reactor, } \\
1^{\text {st }} \text { wall conditions) }\end{array}$ & $\begin{array}{c}\text { Fission neutrons } \\
\text { (BOR 60 reactor) }\end{array}$ & $\begin{array}{c}\text { High energy protons } \\
\text { (590 MeV proton accelerator) }\end{array}$ & $\begin{array}{c}\text { IFMIF (high flux test } \\
\text { module) }\end{array}$ \\
\hline Damage rate $\left(\mathrm{dpa} \mathrm{year}^{-1}\right)$ & $20-30$ & $\sim 20$ & $\sim 10$ & $20-55$ \\
Helium $\left(\mathrm{appm} \mathrm{dpa}^{-1}\right)$ & $10-15$ & $=1$ & $\sim 130$ & $10-12$ \\
Hydrogen $\left(\mathrm{appm} \mathrm{dpa}^{-1}\right)$ & $40-50$ & $=10$ & $\sim 800$ & $40-50$ \\
\hline
\end{tabular}

considering the high energy of fusion neutrons. The term "low activation material" is often used for those which allow hands-on maintenance and minimize waste disposal. In general, fusion relevant alloy development involves resistance to irradiation effects and higher temperature performance ability including structural and functional requirements.

Many studies were conducted in 1980 on type 316 austenitic stainless steels, including effects of fusion relevant $\mathrm{He}$ production and displacement damage on properties and microstructural stability (Zinkle, 2005). Austenitic stainless steels are reported to have higher swelling due to He bubbles generated from Ni transmutation reaction than ferritic martensitic steels. The alloy development thus shifted to high strength $\mathrm{Fe}$-Cr-based steels with $2 \frac{1}{4} \mathrm{Cr}$ to $12 \mathrm{Cr}$ steels with different alloying elements for purpose of microstructure strengthening (Klueh and Harries, 2001). The strengthening mechanism was the formation of carbides of $\mathrm{V}, \mathrm{Cr}, \mathrm{Nb}$, etc. at the prior austenite grain boundaries and within the grains (on lath boundaries). Typical composition for ferritic martensitic alloys being developed in India for fusion reactor applications is listed in Table 5. Elements with long half-life transmutants such as $\mathrm{Ni}, \mathrm{Mo}, \mathrm{Nb}, \mathrm{Cu}$, $\mathrm{Co}, \mathrm{Al}, \mathrm{N}$, etc. have been replaced by low activation counterparts viz. $\mathrm{Mn}, \mathrm{W}, \mathrm{Ta}$ and $\mathrm{C}$ so that the steels can be safely handled after a shorter cooling period as against cooling time of 1000 years required for conventional $\mathrm{Cr}-\mathrm{Mo}-\mathrm{Ni}-\mathrm{Nb}$ containing ferritic martensitic steels (Saroja et al., 2011). Such steels are produced by vacuum induction melting (VIM) followed by vacuum arc refining (VAR) method. Vacuum techniques are used since undesirable elements having high vapour pressure are readily
Table 5: Composition of Indian RAFM steel [Ref: Saroja $e t$ al. (2011)]

\begin{tabular}{lccccc}
\hline $\begin{array}{l}\text { Element/ } \\
\text { steel }\end{array}$ & $\begin{array}{c}\text { Indian } \\
\text { RAFM }\end{array}$ & $\begin{array}{c}\text { Eurofer } \\
97\end{array}$ & $\begin{array}{c}\text { Element/ } \\
\text { steel }\end{array}$ & $\begin{array}{c}\text { Indian } \\
\text { RAFM }\end{array}$ & $\begin{array}{c}\text { Eurofer } \\
97\end{array}$ \\
\hline $\mathrm{Cr}$ & 9.04 & $8.5-9.5$ & $\mathrm{~B}$ & 0.0005 & $<0.001$ \\
$\mathrm{C}$ & 0.08 & $0.09-0.12$ & $\mathrm{Ti}$ & $<0.005$ & $<0.01$ \\
$\mathrm{Mn}$ & 0.55 & $0.2-0.6$ & $\mathrm{Nb}$ & 0.001 & $<0.001$ \\
$\mathrm{~V}$ & 0.22 & $0.15-0.25$ & $\mathrm{Mo}$ & 0.001 & $<0.005$ \\
$\mathrm{~W}$ & 1.00 & $1.00-1.20$ & $\mathrm{Ni}$ & 0.005 & $<0.005$ \\
$\mathrm{Ta}$ & 0.06 & $0.05-0.09$ & $\mathrm{Cu}$ & 0.001 & $<0.005$ \\
$\mathrm{~N}$ & 0.0226 & $0.015-0.045$ & $\mathrm{Al}$ & 0.004 & $<0.01$ \\
$\mathrm{O}$ & 0.0057 & $<0.01$ & $\mathrm{Si}$ & 0.09 & $<0.05$ \\
$\mathrm{P}$ & 0.002 & $<0.005$ & $\mathrm{Co}$ & 0.004 & $<0.005$ \\
$\mathrm{~S}$ & 0.002 & $<0.005$ & $\mathrm{As}+\mathrm{Sb}+$ & $<0.03$ & $<0.05$ \\
& & & $\mathrm{Sn}+\mathrm{Zr}$ & & \\
\hline
\end{tabular}

volatilized during vacuum melting. A typical RAFMS microstructure as indicated in Fig. 6 involves lath martensite boundaries packed in a prior austenite grain. The $\mathrm{M}_{23} \mathrm{C}_{6}$ type carbides are observed to be segregated on prior austenite grain boundaries while the MX type precipitates are present on lath boundaries within prior austenite grains, and such precipitates render strengthening effect to the steel structure. An advancement of this alloy is the oxide dispersion strengthened (ODS) ferritic martensitic steels (Paúl et al., 2005). Particle reinforcement is one of the reliable strengthening mechanisms of FM steels. In such steels, particle reinforcement is provided by addition of minor quantities of nano-sized yttria $\left(\mathrm{Y}_{2} \mathrm{O}_{3}\right)$ powders. Such ODS steels can be manufactured by 


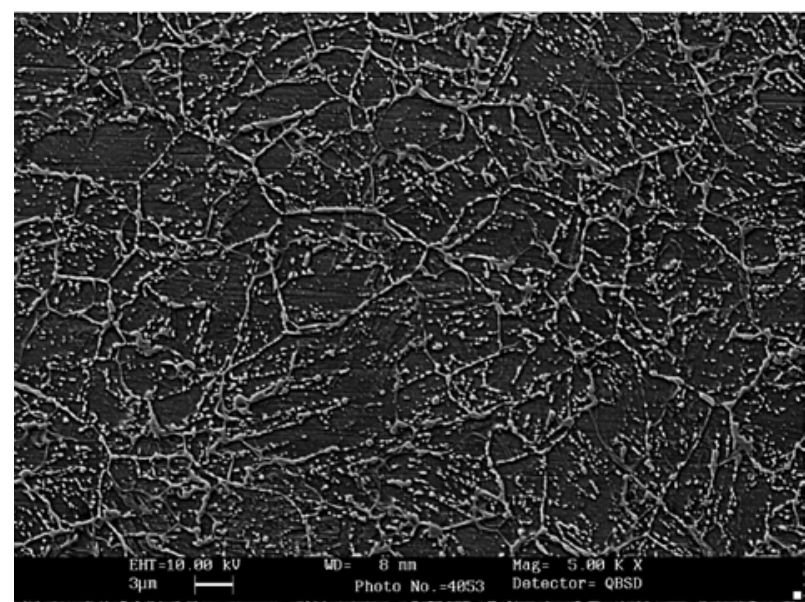

Fig. 6: Microstructure of RAFM steel observed under SEM. Note the carbide precipitation around prior austenite grain boundaries. Minor precipitates within prior austenite grains are indicative of lath martensite boundary

powder metallurgical route followed by hot isostatic pressing to compact shapes.

\subsubsection{Vanadium Alloys}

In a blanket module, liquid metal flow through structural material and presence of ceramic breeder and neutron multiplier need to be handled through the right choice of candidate material. Vanadium alloys are such that they not only have excellent compatibility with $\mathrm{Li}$, but also provide room for high operating temperatures and eliminate the need of ceramic breeders or neutron multipliers (Chen et al., 2011). Vanadium alloys are one of the candidate materials for structural components of blanket modules in the fusion reactor owing to their high temperature strength, high thermal stress factor, low long-term activation, excellent compatibility against $\mathrm{Li}$, etc. The vanadium alloy with $\mathrm{V}-4 \mathrm{Cr}-4 \mathrm{Ti}$ type composition has been developed for fusion blanket applications by US, Japan, Russia and China (Muroga et al., 2002; Chen et al., 2011). There are two ways to improve the strength of V-alloys; one of the methods involves increase in amount of alloying elements such as $\mathrm{Cr}$, etc. Addition of $\mathrm{Al}$ and $\mathrm{W}$ as alloying elements in $\mathrm{V}-4 \mathrm{Cr}-4 \mathrm{Ti}$ alloy has also been known to enhance the mechanical properties of the alloy. The other strengthening mechanism is to produce fine-grained and particledispersed V-alloys using mechanical alloying.
It is important to note that the V-Cr-Ti alloy will endure severe hardening and loss of strain hardening capability by neutron irradiation below $400^{\circ} \mathrm{C}$. Also the mechanical strength of reference $\mathrm{V}-4 \mathrm{Cr}-4 \mathrm{Ti}$ alloy is not as high as FM steels at $<\sim 600^{\circ} \mathrm{C}$, although it has higher strength at higher temperature up to $\sim 750^{\circ} \mathrm{C}$. Efforts are being made to expand the operating temperature window and improve the mechanical properties as well. Such V alloys are specifically considered candidates for $\mathrm{Li}-\mathrm{V}$ blanket concepts where liquid $\mathrm{Li}$ is flowing up to $700^{\circ} \mathrm{C}$ in $\mathrm{V}$ alloy channels with corrosion rates as low as $7.5 \mu \mathrm{m} /$ year. V-alloys are thus an attractive candidate for advanced self-cooled fusion blanket concepts such as Li/V. However, issues such as irradiation creep and He embrittlement behaviour still remain unsolved.

\section{Status of Materials Development in India}

Institute for Plasma Research (IPR), Gandhinagar initiated the plasma physics programme in 1982 and developed "Aditya" which is India's first tokamak system. Subsequently, IPR started developing a steady state tokamak (SST-1) which is under final stages of completion. With passage of time, as India participated in ITER programme (November 2006), the activities towards technological development for fusion reactor were accelerated. Many activities pertaining to development of fusion reactor materials have been initiated at Indira Gandhi Centre for Atomic Research (IGCAR), Bhabha Atomic Research Centre (BARC) and Institute for Plasma Research (IPR).

Research on first wall and divertor development activities at IPR involves materials development and processing studies of $\mathrm{W}, \mathrm{W}$-based alloys, CFC, $\mathrm{CuCrZr}$ alloy, their joining studies and the performance tests such as high heat flux testing (Khirwadkar et al., 2011; Singh et al., 2011; Patil et al., 2013). Reduced activation ferritic martensitic steels have been developed for the Indian TBM programme as per the composition specified in Table 5 (Saroja et al., 2011). Physical metallurgy of the developed Indian RAFMS has been reported by a few studies (Raju et al., 2009; Raj et al., 2010). Studies related to the development of blanket relevant materials such as RAFM steels, ceramic breeders $\left(\mathrm{Li}_{2} \mathrm{TiO}_{3}\right)$, 
compatibility studies of liquid breeder with structural materials under magnetic field, neutronics studies and development of simulation codes, welding and joining techniques, etc. have been reported (Rajendra Kumar et al., 2012). Activities related to development of alumina-based coatings $\left(\mathrm{Al}_{2} \mathrm{O}_{3}+\mathrm{FeAl}\right)$ for blanket applications have been extensively studied and developed by the authors (Jamnapara et al., 2012a; 2014a). Attempts have been made to explore the insulation properties of alumina films grown by thermal and plasma processing. Plasma grown alumina films on FeAl surfaces had been found to yield improved dielectric properties as compared to thermally grown alumina films (Jamnapara, 2015a). In continuation to this, $\alpha-\mathrm{Al}_{2} \mathrm{O}_{3}+$ FeAl-based coatings on P91 steels have been successfully generated using hot dip aluminizing followed by normalizing and tempering treatments using plasma oxidation process. A novel patented concept of using plasma as an oxidation tool has been developed so as to accelerate the transformation of metastable $\theta-\mathrm{Al}_{2} \mathrm{O}_{3}$ to $\alpha-\mathrm{Al}_{2} \mathrm{O}_{3}$ (Jamnapara et al., 2015b). The compatibility of such alumina coatings generated by thermal processing and plasma oxidation treatment against $\mathrm{Pb}-17 \mathrm{Li}$ have been conducted at $550^{\circ} \mathrm{C}$ for 1000 hours under static mode (Jamnapara et al., 2014b). The plasma processed stable $\alpha-\mathrm{Al}_{2} \mathrm{O}_{3}$ has been found to be immune against $\mathrm{Pb}-17 \mathrm{Li}$ for 1000 hours duration with no weight loss, while the bare P91 substrate revealed $7.23 \mathrm{mg} / \mathrm{cm}^{2}$ weight loss which was $\sim 7 \mu \mathrm{m}$ of substrate degradation as confirmed by SEM-EDS. Further tests under dynamic $\mathrm{Pb}$-17Li conditions are being planned in near future. FeAl-based coatings for welded areas of blanket structures using electrospark deposition technique have also been explored on a preliminary level by the authors (Jamnapara et al., 2012a). Interesting features of a quasi-amorphous interface without any grain boundary has been observed which could be a potential barrier for hydrogen permeation. The electrospark deposition technique can also be explored as a possible coating process for first wall applications needing $\mathrm{W}$ coatings.

Materials development activities for extreme environments such as nuclear fusion would not be possible without nuclear grade materials testing, characterization and validation facilities. Neutron irradiation sources equivalent to $14.1 \mathrm{MeV}$ are not available and need to be set up. An International Fusion Materials Irradiation Facility (IFMIF) is being conceptualized (Garin and Sugimoto, 2008) and planned for validation trials of materials to be qualified for fusion environment. The IFMIF is being planned by EU, Japan, Russia and USA; and being managed by the International Energy Agency. The primary mission of IFMIF is to generate a materials database to be used for design and construction of various components of DEMO-type reactors. IFMIF will be an accelerator-based, high-energy neutron source mainly composed of two $125 \mathrm{~mA}$ deuteron accelerators and a flowing liquid Li target (Baluc et al., 2011). In the high flux test module of the IFMIF, the irradiation conditions will be very close to the ones expected in a DEMO type reactor at the level of first wall, at least in terms of damage rate $(22-55 \mathrm{dpa} /$ year) and rates of He production (10-12 appm dpa ${ }^{-1}$ ) and hydrogen (40-50 appm dpa ${ }^{-1}$ ). In addition to static material interaction in the high flux test module, more sophisticated in situ creep-fatigue tests on structural materials and in situ tritium release experiments on different tritium breeding materials are foreseen in medium flux test module, where a damage rate of 1$20 \mathrm{dpa} /$ year will be reached (Baluc et al., 2011). India will need to actively participate in such international facility to build a domestic fusion reactor.

\section{Indian Fusion Reactor Programme}

The energy requirement of India is expected to grow by almost 10 times of the present requirement in the next 50 years. Out of the installed capacity of 120 GWe power, $95.5 \%$ is produced through thermal and hydro while just $2 \%$ is produced through nuclear energy. With the introduction of the new concepts of fission technology in India viz. prototype FBR and thorium reactors for near future, fusion is viewed as natural advanced successor technology to fission for producing large amounts of electricity (Srinivasan and Deshpande, 2008). The Indian plasma physics programme started in 1982 resulting in the inception of the Institute for Plasma Research (IPR) at Gandhinagar, Gujarat, India. India's first tokamak device "Aditya" was demonstrated in 1989. Later on, the Steady State Tokamak-1 (SST-1) programme was 
initiated at IPR. The SST-1 machine (designed for hydrogen plasma) is mainly focused on studies related to plasma physics and supporting instrumentation and subsystems. With India's participation in the ITER project, the D-T fusion reactor technology will be enhanced and would be useful for India's domestic fusion reactor programme. The Indian TBM programme has aggressively progressed with the joint efforts of IPR, IGCAR, BARC and other organizations in India. The Indian TBM concept is to be tested in one half port of ITER reactor at Cadarache, France.

As a roadmap towards the Indian fusion programme (Rajendra Kumar, 2012), India has proposed a next stage of SST-1 machine: a D-T machine named Stead State Tokamak-2 ('SST-2'). SST-2 will be a medium-sized tokamak reactor with D-T operation. SST-2 operation will enable the testing of various indigenously built subsystems of the fusion reactor, specifically addressing tritium breeding and handling issues, robotics and remote handling, alpha particle issues, fusion materials development, etc. Further, the SST-2 will address the availability of a machine for breeding blankets and testing and validation of novel materials developed for DEMO applications. The SST-2 will become the stepping stone towards realization of a DEMO reactor.

\section{ITER Project and India's Role}

The first conceptual design of ITER device was started in April 1988. A revised design was finalized in 2001 by the ITER Council. Owing to the domestic steady state tokamak programme, India joined ITER in December 2005 and the ITER agreement between seven partners was signed in November 2006. Thereafter, the ITER design and construction work has been in progress. It was projected (Holtkamp, 2009) that ITER would initiate its first plasma shot in 2018. The divertor which was initially a carbon-based (CFC) divertor has now been confirmed as full tungsten-based divertor (Merola et al., 2014). This is because carbon is not permitted during nuclear use owing to the potential risk of rapid generation of tritium dust. Thus, the replacement of a CFC divertor by a full $\mathrm{W}$ divertor is due to safety reasons as well as cost reduction and maintenance. In 2009, the ITER Council created a high-level advisory body, "The TBM Programme Committee", was appointed to ensure the on-time delivery of the test blanket systems at the ITER site (Giancarli et al., 2012). The test blanket module system concepts proposed by the seven partners of ITER underwent a final design review in 2013 and is now entering the engineering and procurement phase (Merola et al., 2014).

India is one of the seven partners and shares some cost of components of ITER. A schematic view of the in-kind contributions of the seven partners is shown in Fig. 7, wherein India's contribution has also been indicated (Kaname, 2010). 'ITER India', is a project governed by an empowered board under the Department of Atomic Energy, Government of India, and is committed to the delivery of the components to be provided by India as "in-kind contribution". The contribution to TBM for ITER excludes the contributions shown in Fig. 7.

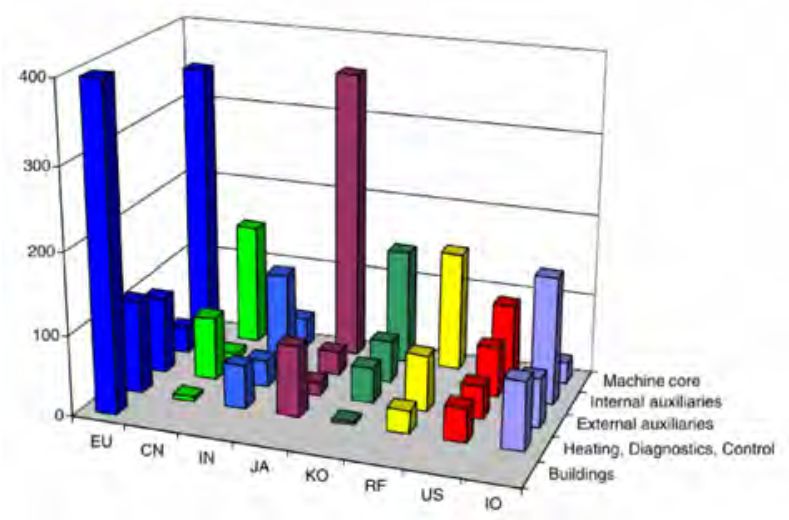

Fig. 7: Contribution of ITER partners to ITER [Ref: Kaname (2010)]

\section{Conclusions}

The fusion reactor programme has taken a large leap owing to the increasing energy demands and the limited reliability of energy sources. The extreme environments in fusion reactors pose a challenge to the materials research and development community, which is being worked upon aggressively. Without appropriate materials, we cannot expect a fusion reactor. While most of the materials research is being focused on first wall, divertor, breeder and structural 
materials, appropriate thrust is also being made on setting up of fusion grade testing and validation facilities. With India's domestic power demand, it would need to strengthen its domestic fusion programme as next generation energy source. Materials research and development activities are thus inevitable for a better tomorrow.

\section{References}

Baluc N (2006) Materials for fusion power reactors Plasma Phys Control Fusion 48 B165-B177

Baluc N et al. (2007) Status of R\&D activities on materials for fusion power reactors $\mathrm{Nucl}$ Fusion 47 S696-S717

Baluc N, R et al. (2011) From materials development to their test in IFMIF: an overview Nucl Fusion 51113006 (10 pp)

Bellanger G (2008) Localized corrosion of 316L stainless steel in tritiated water containing aggressive radiolytic and decomposition products at different temperatures $\mathrm{J} \mathrm{Nucl}$ Mater 374 20-31

Bloom E E et al. (2007) Critical questions in materials science and engineering for successful development of fusion power $J$ Nucl Mater 367-370 1-10

Bornschein B et al. (2013) Tritium management and safety issues in ITER and DEMO breeding blankets Fusion Eng Des $\mathbf{8 8}$ 466-471

Chen J M et al. (2011) Overview of the vanadium alloy researches for fusion reactors J Nucl Mater 417 289-294

Garin P and M Sugimoto (2008) Status of IFMIF Design and R\&amp;D Fusion Eng Des 83 971-975

Giancarli L M et al. (2012) Overview of the ITER TBM Program Fusion Eng Des 87 395-402

Griffith S (2008) ITER Divertor under final review ITER Newsline Retrieved 08 December 2008, from http://www.iter.org/ newsline/61/122

Holtkamp N (2009) The status of the ITER design Fusion Engineering and Design 84 98-105

Jamnapara N I (2013) Development of aluminized coatings on $\mathrm{P} 91$ steel for $\mathrm{Pb}-\mathrm{Li}$ environment in fusion reactors. $\mathrm{Ph} . \mathrm{D}$ Thesis, IIT Bombay, Mumbai, pp 16-18

Jamnapara N I et al. (2012a) Effect of Si on morphology of alumina scales Surf Eng 28 693-699

Jamnapara N I et al. (2015a) Comparative analysis of insulating properties of plasma and thermally grown alumina films on electrospark aluminide coated 9Cr steels Surf Coat Technol 266 146-150

Jamnapara N I et al. (2012) Microstructural studies of electrospark deposited aluminide coatings on 9Cr steels Surf Eng $\mathbf{2 8}$
700-704

Jamnapara N I et al. (2015b) Phase transformation of alumina coating by plasma assisted tempering of aluminized P91 steels J Nucl Mater 464 73-79

Jamnapara N I et al. (2014a) Al2O3 films grown by glow discharge plasma aluminising Surf Eng 30 467-474

Jamnapara N I et al. (2014b) Compatibility study of plasma grown alumina coating with $\mathrm{Pb}-17 \mathrm{Li}$ under static conditions J Nucl Mater 455 612-617

Kaname I (2010) ITER on the road to fusion energy Nucl Fusion 50014002 (10 pp)

Khirwadkar S S et al. (2011) Fabrication and characterization of tungsten and graphite based PFC for divertor target elements of ITER like tokamak application Fusion Eng Des 86 1736-1740

Klueh R L and D R Harries (2001). High chromium ferritic martensitic steels for nuclear applications. ASTM Publishing, PA, USA

Krauss W et al. (2012) TBM testing in ITER: Requirements for the development of predictive tools to describe corrosionrelated phenomena in HCLL blankets towards DEMO Fusion Eng Des 87 403-406

Kumar E R et al. (2008) Preliminary design of Indian Test Blanket Module for ITER Fusion Eng Des 83 1169-1172

Merola M et al. (2014) Overview and status of ITER internal components Fusion Eng Des 89 890-895

Muroga T et al. (2002) Vanadium alloys - overview and recent results J Nucl Mater 307-311 547-554

Naujoks D (2010) General criteria and operation limits of a steadystate fusion reactor with respect to plasma-material interaction AIP Conf Proc 1237 3-17

Neu R (2010) Benefits and challenges of the use of high-Z plasma facing materials in fusion devices AIP Conf Proc 1237 6277

Patil Y et al. (2013) High heat flux performance of brazed tungsten macro-brush test mock-up for divertors J Nucl Mater 437 326-331

Paúl A et al. (2005) Microstructural characterization of EuroferODS RAFM steel in the normalized and tempered condition and after thermal aging in simulated fusion conditions Fusion Eng Des 75-79 1061-1065

Philipps V (2011) Tungsten as material for plasma-facing components in fusion devices $J$ Nucl Mater 415 (1, Supplement) S2-S9

Raj B et al. (2010) Progress in the development of reduced activation ferritic-martensitic steels and fabrication technologies in India Fusion Eng Des 85 1460-1468 
Rajendra Kumar E (2012) Indian DEMO blanket activities and blanket materials readiness, gaps and needed R\&D. 1st IAEA DEMO programme workshop, UCLA Faculty Center, California, USA

Rajendra Kumar et al. (2012) Overview of TBM R\&D activities in India Fusion Eng Des 87 461-465

Raju S et al. (2009) Measurement of transformation temperatures and specific heat capacity of tungsten added reduced activation ferritic-martensitic steel J Nucl Mater 389385 393

Rieth M et al. (2013) Recent progress in research on tungsten materials for nuclear fusion applications in Europe $\mathrm{J} \mathrm{Nucl}$ Mater 432 482-500

Ronald L and Klueh D R H (2001) High-Chromium Ferritic and Martensitic Steels for Nuclear Applications. West Conshohocken, PA, USA, ASTM

Rotti C et al. (2014) Establishing ITER-grade properties in CuCrZr: The Indian experience Fusion Sci Technol $65205-$ 211

Saroja S et al. (2011) Development and characterization of advanced $9 \mathrm{Cr}$ ferritic/martensitic steels for fission and fusion reactors J Nucl Mater 409 131-139

Schmid K and J Roth (2010) Erosion processes due to energetic particle-surface interaction AIP Conf Proc 1237 18-31
Singh K P et al. (2011) Pre-qualification of brazed plasma facing components of divertor target elements for ITER like tokamak application Fusion Eng Des 86 1741-1744

Smith D L et al. (2002) Progress in coating development for fusion systems Fusion Eng Des 61-62 629-641

Srinivasan R and S P Deshpande (2008) Strategy for the Indian DEMO design Fusion Eng Des 83 889-892

Suri A K et al. (2010) Materials issues in fusion reactors $J$ Phys: Conf Ser 208012001 (16 pp)

Tavassoli A A F (2002) Present limits and improvements of structural materials for fusion reactors - A review $\mathrm{J} \mathrm{Nucl}$ Mater 302 73-88

Wong C P et al. (2001) Evaluation of the tungsten alloy vaporizing lithium first wall and blanket concept Fusion Technol 39 $815-822$

Yan Q.-Z et al. (2013) Status of R\&D on plasma facing materials in China J Nucl Mater 442 S190-S197

You J H et al. (2013) Thermal and mechanical properties of infiltrated $\mathrm{W} / \mathrm{CuCrZr}$ composite materials for functionally graded heat sink application J Nucl Mater 438 1-6

Zinkle S J (2005) Fusion materials science: Overview of challenges and recent progress Phys Plasmas 12 058101-058108. 